\title{
Hubungan Inisiasi Menyusui Dini (IMD) terhadap Status Gizi Bayi Dibawah Dua Tahun (BADUTA) di Puskesmas Malaka Kecamatan Lalabata Kabupaten Soppeng
}

\author{
Aspiati Haji Ali ${ }^{1}$, Arlin Adam², Andi Alim ${ }^{3}$ \\ ${ }^{1,2,3)}$ Fakultas Kesehatan Masyarakat, Universitas Pejuang Republik Indonesia \\ E-mail: ${ }^{1}$ rsaspiati@gmail.com, ${ }^{2}$ arlin_adam@yahoo.com, ${ }^{3}$ andi_alimbagu@yahoo.co.id
}

\begin{abstract}
ABSTRAK
Cakupan Inisiasi Menyusui Dini (IMD) untuk Kabupaten Soppeng berdasarkan data survei pemantauan status gizi masih tergolong rendah bila di bandingkan dengan target nasional sebesar 80\%. Sehingga diduga berdampak pada prevalensi kejadian gizi kurang sebesar 22,6\%, Stunting 38,7\%, Kurus 7,7\% dan Gemuk 4,5\%. Tujuan pada penelitian ini adalah untuk melihat hubungan IMD terhadap status gizi bayi di bawah dua tahun (baduta) di Pusekesmas Malaka Kecematan Lalabata Kabupaten Soppeng Propinsi Sulawesi Selatan. Penelitian ini menggunakan metode survei dengan pendekatan analisis statistik dengan desain cross sectional study. Besar sampel dalam penelitian ini sebesar 67 baduta dengan pengambilan sampel secara acak sederhana atau simple random sampling. Penelitian ini dilaksanakan di wilayah kerja Puskesmas Malaka Kelurahan Lapajung Kecamatan Lalabata pada bulan April sampai dengan Juni 2019. Pengolahan data diolah menggunakan SPSS dengan uji kolmogrov-smirnov dengan nilai probabilitas 95\%. Hasil analisis status gizi baduta berdasarkan berat badan menurut umur rata-rata memiliki status gizi baik sebanyak 85,1\% dan yang kurang serta lebih hanya 10,4\% dan $4,5 \%$, dan berdasarkan status gizi menurut tinggi badan menurut umur rata-rata berstatus gizi normal sebanyak $65,7 \%$ dan yang pendek dan sangat pendek masing-masing hanya 19,4\% dan 7,5\%. Sedangkan, berdasarkan berat badan menurut tinggi badan rata-rata berstatus gizi normal sebanyak 83,6\%, 11,9\% yang kurus, dan 3,0\% yang gemuk. Dari hasil analisis bivariat yang didapatkan bahwa tidak terdapat hubungan Inisiasi Menyusu Dini (IMD) terhadap status gizi anak di wilayah kerja Puskesmas Malaka Kelurahan Lapajung. Hal ini terjadi dikarenakan masih banyak faktor yang mempegaruhi status gizi selain IMD. Maka dari itu dilakukan penelitian lanjutan dengan menambah variabel penelitian yaitu sanitasi dan pola asuh.
\end{abstract}

Kata Kunci: Inisiasi menyusi dini, status gizi, bayi dibawah dua tahun

\begin{abstract}
Early Initiation Coverage (IMD) for Soppeng District based on survey data on nutritional status monitoring is still relatively low compared to the national target of $80 \%$. So it is thought to have an impact on the prevalence of malnutrition by $22.6 \%$, stunting $38.7 \%$, skinny $7.7 \%$ and fat $4.5 \%$. The purpose of this study was to look at the relationship between Early Breastfeeding Initiation and nutritional status of infants under two years at the Malaka community health centre, Lalabata District, Soppeng Regency, South Sulawesi Province. This study used a survey method with a statistical analysis approach and cross-sectional study design. The sample size in this study was 67 people which obtained through simple random sampling. This research was conducted in the working area of the Malaka Health Center in Lapajung Sub-district, Lalabata District from April to June 2019. The data was processed by using the Kolmogorov-Smirnov test with a probability value of 95\% in SPSS. The results of the analysis of nutritional status in infants under two years based on body weight according to the average age showed that $85.1 \%$ have good nutritional status, $10.4 \%$ less nutritional status and $4.5 \%$ over nutritional status. The nutritional status based on height according to the average age showed $65.7 \%$ had normal height, $19.4 \%$ short height and $7.5 \%$ poor height. Meanwhile, based on body weight according to a height, the result showed that $83.6 \%$ had normal weight, $11.9 \%$ under weight, and 3.0\% overweight. From the results of the analysis it was found that there is no relationship between Early Breastfeeding Initiation (IMD) and the nutritional status of infants under two years in the working area of the Malaka Puskesmas Lapajung Village. This happens because there are still many factors that affect nutritional status in addition to Early Breastfeeding Initiation. Therefore, it is better to conduct further research by adding research variables including sanitation and parenting.
\end{abstract}

Keywords: Early breastfeeding initiation, nutritional status, babies are brought for two years

*Korespondensi Author: Andi Alim, Fakultas Kesehatan Masyarakat, Universitas Pejuang Republik Indonesia,andi_alimbagu@yahoo.co.id,Telp.085240911659 


\section{PENDAHULUAN}

Kualitas sumber daya manusia (SDM) yang baik merupakan indikator pembangunan dari berbagai aspek kehidupan dan status gizi merupakan faktor yang sangat berpengaruh terhadap perkembangan tersebut (1). Pemberian ASI yang diawali ketika inisiasi menyusu dini (IMD) mampu menahan risiko terjadinya kematian pada bayi. Hal ini terjadi karena kandungan pada ASI yaitu faktor protektif dan nutrisi yang tepat pada bayi dan menjamin status gizi bayi ${ }^{(2)}$.

Berdasarkan data Riskesdas 2010 di Indonesia, pemberian ASI di kurang dari satu jam pasca kelahiran atau Inisiasi Menyusui Dini (IMD) sebanyak 29,3\%, ASI 1-6 jam pasca kelahiran sebanyak $40,7 \%$, yang memberikan ASI selama 7-23 jam pasca kelahiran sebanyak 7,6\%, pemberian ASI selama 24-47 jam pasca kelahiran sebanyak $11,3 \%$ dan $\geq 48$ jam pasca kelahiran sebanyak $11,1 \%$. Begitu pula Data Riskesdas 2013 untuk Sulawesi Selatan, di kurang dari satu jam pasca kelahiran atau Inisiasi Menyusui Dini (IMD) sebanyak 44,9\%, ASI 1-6 jam pasca kelahiran sebanyak 20,6\%, yang memberikan ASI selama 7-23 jam pasca kelahiran sebanyak $3,7 \%$, pemberian ASI selama 24-47 jam pasca kelahiran sebanyak $10,2 \%$ dan $\geq 48$ jam pasca kelahiran sebanyak $15,1 \%$.

$$
\text { Noviati dan Mujiati }
$$
mengemukakan bahwa faktor tingginya tingkat keberhasilan pelaksanaan IMD dikarenakan adanya sinergi antar tenaga kesehatan dalam pelaksanaan persalinan yang aman dan nyaman bagi ibu dan bayi, pengetahuan ibu yang baik mengenai manfaat IMD serta dukungan suami dan tenaga kesehatan mulai dari proses persalinan sampai proses IMD selesai dilakukan (3).

Untuk cakupan IMD untuk kabupaten Soppeng menurut data survei pemantauan status gizi pada tahun 2017 masih tergolong rendah yaitu > 1 jam $(5,0 \%)$, dan < 1 jam (55,0\%). Dari data ini mampu dinilai bahwa cakupan IMD di Sulawesi Selatan khususnya di Kabupaten Soppeng terbilang rendah berdasarkan target nasional sebesar $80 \%{ }^{(4)}$.
Ridzal, M. Hadju, V, \& Rochimiwati (2013) mengemukakan bahwa

Ketidakberhasilan IMD dapat menganggu proses pemberian ASI eksklusif. Anak yang tidak diberikan ASI Eksklusif akan mempengaruhi status gizi. Status gizi adalah kondisi tubuh dari akibat mengkonsumsi makanan dan penggunaan status gizi. Konsumsi makanan dan penggunaan zat-zat gizi dalam tubuh sangat mempengaruhi status gizi ${ }^{(5)}$. Jika tubuh mendapatkan cukup zat gizi dan dimanfaatkan secara efesien maka akan berdampak pada perumbuhan fisik, perkembangan otak, kemampuan kerja dan kesehatan secara umum pada tingkat yang lebih baik (6). Adapun indikator status gizi yaitu berat badan menurut umur $(\mathrm{BB} / \mathrm{U})$, tinggi badan menurut umur $(\mathrm{TB} / \mathrm{U})$, dan berat badan menurut tinggi badan (BB/TB).

Gizi kurang biasanya berkaitan dengan susunan hidangan yang tidak seimbang dan mengakibatkan kebutuhan anak tidak tercukupi gizi ${ }^{(7)}$. Gizi kurang atau gizi buruk pada balita dapat berakibat terganggunya pertumbuhan jasmani dan kecerdasan mereka. Kalau cukup banyak orang yang termasuk golongan ini masyarakat yang bersangkutan sulit sekali berkembang. Dengan demikian jelas masalah gizi merupakan masalah bersama dan semua keluarga harus bertindak atau berbuat sesuatu bagi perbaikan gizi ${ }^{(8)}$.

Secara garis besar masalah gizi disebabkan oleh dua faktor langsung yaitu tingkat pengetahuan, tingkat pendapatan, pola asuh (IMD, pemberian ASI Eksklusif, pemberian MP ASI), ketersediaan pangan, pelayanan kesehatan, sosial budaya dan lingkungan ${ }^{(9)}$.

Berdasarkan Laporan Gizi Global 2014 Indonesia berada diantara 31 negara yang tidak akan mencapai target global untuk menurunkan angka kurang gizi di tahun 2025. Data pemerintah menunjukkan $37 \%$ anak balita menderita stunting, $12 \%$ menderita wasting (terlalu kurus untuk tinggi badan mereka) dan $12 \%$ mengalami kelebihan berat badan (10)

Hal ini sejalan dengan Pemantauan Status Gizi Kementrian Kesehatan Republik Indonesia pada tahun 2016, sepanjang tahun 2015 sampai 
2016 telah terjadi penurunan angka prevalensi kasus gizi kurang $(\mathrm{BB} / \mathrm{U})$ dan kurus $(\mathrm{BB} / \mathrm{PB})$ sebesar $1,0 \%$ dan $0,8 \%$ (dari 18,80 pada tahun 2015 menjadi 17,80 pada tahun 2016; untuk prevalensi kurus pada tahun 2015 sekitar $(11,90 \%)$ dan menurun pada tahun 2016 menjadi $(11,10 \%)$. Untuk prevalensi stunting (TB/U) terjadi juga penurunan dari 29,00 pada tahun 2015 dan menurun pada tahun $2016(27,50 \%)$. Walaupun terjadi penurunan namun angka prevalensi dari indikator status gizi di atas masih tergolong tinggi dari ketentuan WHO yaitu prevalensi balita pendek kurang dari $20 \%$ dan prevalensi balita kurus kurang dari $5 \%{ }^{(11)}$.

Data prevalensi status gizi wilayah Kabupaten Soppeng Berdasarkan data pemantau status gizi pada tahun 2017 menunjukkan bahwa prevalensi gizi buruk sekitar 22,6\%, Stunting atau pendek sekitar 38,7\%, kurus sekitar 7,7\%, dan gemuk $(4,5 \%)^{(4)}$.

Berdasarkan uraian diatas peneliti tertarik untuk melakukan penelitian yang berjudul "hubungan Inisiasi Menyusu Dini (IMD) Terhadap Status Gizi Balita (Studi Analitik Di Puskesmas Malaka Kelurahan Lapajung Kecamatan Lalabata Kabupaten Soppeng Tahun 2018)

\section{METODOLOGI}

\section{Desain Penelitian}

Penelitian ini merupakan jenis penelitian survei analitik dengan menggunakan pendekatan cross sectional study.

\section{Lokasi dan Waktu Penelitian}

Lokasi penelitian ini dilakukan di wilayah kerja Puskesmas Malaka Kelurahan Lapajung, Kecamatan Lalabata, Kabupaten Soppeng. Sedangkan, waktu penelitian dilaksanakan mulai dari 12 April - 26 Juni 2019.

\section{Populasi dan Sampel}

Populasi dalam penelitian ini adalah seluruh balita berusia 0-24 bulan yang berada di wilayah kerja Puskesmas Malaka Kelurahan Lapajung, Kecamatan Lalabata, Kabupaten Soppeng dengan jumlah 315 balita. Sedangkan, Sampel adalah seluruh balita usia 0-24 bulan di wilayah kerja Puskesmas Malaka, Kelurahan Lapajung, Kecamatan Lalabata, Kabupaten Soppeng. Metode pengambilan sampel adalah menggunakan teknik simple random sampling dengan metode penentuan jumlah sampel menggunakan rumus slovin, sehingga didapatkan jumlah sampel sebesar 67 baduta. Sampel diacak menggunakan aplikasi www.randomizer.org

\section{Cara Pengumpulan Data}

Cara pengumpulan data sekunder terdiri atas gambaran umum Puskesmas Malaka Kelurahan Lapajung, Kecamatan Lalabata, Kabupaten Soppeng yang diperoleh melalui pencetakan pada profil Puskesmas. Sedangkan, untuk data primer tentang data Inisiasi Menyusu Dini (IMD) diperoleh dengan menilai ketepatan waktu dilakukan IMD dan tehnik/cara pelaksanaannya dengan menggunakan kuesioner. Sedangkan data status gizi diukur dengan menimbang berat badan dengan timbangan injak yang mempunyai tingkat ketelitian $0,5 \mathrm{~kg}$ dan pengukuran tinggi badan dengan microtoise yang mempunyai ketelitian $0,1 \mathrm{~cm}$.

Cara mengukur berat badan pada penelitian ini yaitu meletakkan timbangan injak di lantai yang rata, sebelum menimbang timbangan injak harus dalam posisi jarum pada angka 0 (nol), balita ditimbang dengan melepas sepatu, topi dan meletakkan barang yang di bawa (HP, Mainan, dll), Posisi balita berdiri tegak lurus pandangan lurus ke depan dan kedua kaki berada dalam timbangan, terkahir peneliti membaca angka pada jarum timbangan injak dengan posisi di depan timbangan injak. Dan untuk tata cara mengukur tinggi badan dengan menggunakan Microtoise ${ }^{(9)}$. Sedangkan, Umur balita, diperoleh dengan cara menghitung selisih antara tanggal wawancara dan tanggal lahir balita. ${ }^{(12)}$.

Instrumen penelitian yang digunakan dalam penelitian ini adalah Microtoise, Infantometer, Kuesioner dan alat tulis menulis 


\section{Pengolahan Data}

Pengolahan data pelaksanaan Inisiasi Menyusu Dini (IMD), kuesioner terdiri dari 6 pertanyaan dari jawaban yang diperoleh kemudian disimpulkan apakah dilakukan IMD atau tidak, data primer untuk balita diperoleh dengan melakukan pengukuran antropometri dengan indeks $\mathrm{BB} / \mathrm{U}, \mathrm{TB} / \mathrm{U}$, dan $\mathrm{BB} / \mathrm{TB}$ kemudian diolah menggunakan aplikasi $W H O$ antro.

\section{Analisis Data}

Analisis uji statistik data dalam menganalisis hubungan IMD terhadap status gizi baduta (studi analitik di Puskesmas Malaka Kelurahan Lapajung, Kecamatan Lalabata, Kabupaten Soppeng Propinsi Sulawesi Selatan) dengan usia 0-24 bulan adalah uji kolmogrovsmirnov dengan $\alpha=0,05$ dengan menggunakan aplikasi SPSS 24.

\section{HASIL DAN PEMBAHASAN Karakteristik responden}

Pada penelitian ini yang menjadi sampel adalah balita usia 0-24 bulan di wilayah kerja Puskesmas Malaka Kelurahan Lapajung, Kecamatan Lalabata, Kabupaten Soppeng, Sampel pada penelitian adalah 67 sampel. Berdasarkan hasil pengumpulan data, diperoleh karakteristik Subjek sebagai berikut:

Tabel 1. Distirbusi subjek berdasarkan usia, suku, pendidikan dan pekerjaan kedua orang tua Responden di wilayah kerja Puskesmas Malaka

Kelurahan Lapajung, Kecamatan Lalabata, Kabupaten Soppeng

\begin{tabular}{lcc}
\hline \multicolumn{1}{c}{ Karakteristik } & n & \% \\
\hline Usia & & \\
0-6 bulan & 6 & 9,0 \\
7-24 bulan & 61 & 91 \\
\hline Suku & & \\
Bugis & 65 & 97,0 \\
Jawa & 2 & 3,0 \\
\hline Pekerjaan Ayah & & \\
PNS/TNI/Polri & 16 & 23,9 \\
Karyawan Swasta & 32 & 47,8 \\
Pedagang & 5 & 7,5 \\
Pengusaha & 6 & 9,0 \\
\hline
\end{tabular}

\begin{tabular}{lcc}
\hline \multicolumn{1}{c}{ Karakteristik } & n & \% \\
\hline Petani & 4 & 6,0 \\
Buruh & 2 & 3,0 \\
Honorer & 2 & 3,0 \\
\hline Pekerjaan Ibu & & \\
PNS/TNI/Polri & 12 & 17,9 \\
Karyawan Swasta & 8 & 11,9 \\
Pensiunan & 1 & 1,5 \\
Ibu Rumah Tangga & 43 & 64,2 \\
Honorer & 3 & 4,5 \\
\hline Pendidikan Ayah & & \\
Tidak Pernah Sekolah & 3 & 4,5 \\
Tamat SD & 8 & 11,9 \\
Tamat SMP & 10 & 14,9 \\
Tamat SMA & 23 & 34,3 \\
Perguruan Tinggi & 23 & 34,3 \\
\hline Pendidikan Ibu & & \\
Tamat SD & 6 & 9,0 \\
Tamat SMP & 8 & 11,9 \\
Tamat SMA & 24 & 35,8 \\
Perguruan Tinggi & 29 & 43,3 \\
\hline Sumber Data Piim
\end{tabular}

Sumber: Data Primer, 2019

Tabel 1 menunjukkan bahwa usia anak yang menjadi responden mayoritas berusia 7 sampai 24 bulan sebanyak 61 orang $(91,0 \%)$, dan yang berusia 0-6 bulan hanya 6 orang $(9,0 \%)$. Sedangkan, untuk tabel suku orang tua menunjukkan bahwa suku dari orang tua sampel adalah mayoritas bersuku Bugis yaitu 65 responden $(97,0 \%)$ dan suku Jawa 2 Responden $(3,0 \%)$

Pada tabel 1 juga menjelaskan bahwa pekerjaan ayah yang menjadi responden adalah rata sebagai karyawasn swasta PNS sebanyak 32 orang $(47,8 \%)$, TNI/POLRI sebanyak 16 orang (23,9\%), pengusaha (hasil bumi/kerajinan/makanan) sebanyak 6 orang $(9,0 \%)$, pedagang (barang/campuran/sayuran/ikan) sebanyak 5 orang $(7,5 \%)$, petani pemilik (tambak/padi) sebanyak 4 orang $(6,0 \%)$, dan yang bekerja sebagai buruh harian (tani/bangunan/tukang kayu/tukang batu) dan honorer masing-masing sebanyak 2 orang $(3,0 \%)$. Sedangkan, untuk pekerjaan ibu sebagian besar bekerja sebagai ibu rumah tangga sebanyak 43 responden $(64,2 \%)$, kemudian yang bekerja sebagai PNS/TNI/POLRI sebanyak 12 orang (17,9\%), 
karyawan swasta sebanyak 8 orang $(11,9 \%)$, honorer sebanyak 3 orang $(4,5 \%)$ dan 1 orang $(1,5 \%)$ bekerja sebagai pensiunan.

Tabel 1 juga menjelaskan tentang pendidikan kedua orang tua bahwa sebagian besar pendidikan orang tua (ayah) adalah tamat perguruan tinggi dan tamat SMA masing-masing 23 orang $(34,3 \%)$ kemudian tamat SMP dan SD masing-masing sebanyak 10 responden $(14,9 \%)$ dan 8 responden $(11,9 \%)$, dan 3 responden $(4,5 \%)$ yang tidak pernah sekolah. Sedangkan, untuk pendidikan ibu sebagian besar pendidikan orang tua (ibu) adalah tamat perguruan tinggi yaitu sekitar 29 responden (43,3\%) kemudian tamat SMA dan SMP masing-masing sebanyak 24 responden $(35,8 \%)$ dan 8 responden $(11,9 \%)$, dan 6 responden $(9,0 \%)$ yang tamat SD.

Tabel 2 Distribusi Responden Berdasarkan Berat Badan Menurut Umur (BB/U), Tinggi Badan Menurut Umur (TB/U), Berat Badan Menurut Tinggi Badan (BB/TB) dan Praktek IMD

\begin{tabular}{lcc}
\multicolumn{1}{c}{ Variabel } & n & \% \\
\hline Status Gizi (BB/U) & 7 & 10,4 \\
Gizi Kurang & 57 & 85,1 \\
Gizi Baik & 3 & 4,5 \\
Gizi Lebih & 5 & \\
\hline Status Gizi (TB/U) & 13 & 19,4 \\
Sangat Pendek & 44 & 65,7 \\
Pendek & 5 & 7,5 \\
Normal & & \\
Tinggi & 1 & 1,5 \\
\hline Status Gizi (BB/TB) & 8 & 11,9 \\
Sangat Kurus & 56 & 83,6 \\
Kurus & 2 & 3,0 \\
Normal & & \\
Gemuk & 18 & 26,9 \\
\hline Praktek IMD & 49 & 73,1 \\
Tidak dilakukan &
\end{tabular}

Sumber: Data Primer, 2019

Berdasarkan penelitian di atas menunjukkan bahwa rata-rata balita yang berada di wilayah Puskesmas Malaka berstatus gizi baik sebanyak 57 orang $(85,1 \%)$, kemudian yang memliliki status gizi kurang dan lebih sebanyak $7(10,4 \%)$ dan $3(4,5 \%)$. Sedangkan, untuk status gizi berdasarkan tinggi badan menurut umur menunjukkan bahwa rata-rata balita yang berada di wilayah Puskesmas Malaka memiliki status gizi normal sebanyak 44 orang $(65,7 \%)$, pendek 13 orang $(19,4 \%)$, kemudian yang tinggi 5 orang $(7,5 \%)$, dan sangat pendek 5 orang $(7,5 \%)$.

Pada tabel 2 diatas juga menunjukkan bahwa rata-rata balita yang berada di wilayah Puskesmas Malaka memiliki status gizi berdasarkan berat badan badan menurut tinggi badan rata-rata berstatus normal sebanyak 56 orang $(83,6 \%)$, kurus 8 orang $(11,9 \%)$, kemudian yang gemuk 2 orang $(3,0 \%)$, dan yang sangat kuru 1 orang $(3,0 \%)$. Sedangkan, praktek inisiasi menyusu dini di wilayah kerja Puskesma Malaka rata-rata telah dilakukan dengan jumlah responden $49(73,1 \%)$, dan tidak melakukan hanya 18 responden $(26,9 \%)$.

\section{Inisiasi Menyusu Dini terhadap status gizi berdasarkan berat badan menurut umur (BB/U)}

Inisiasi menyusu dini (IMD) merupakan program dari kementrian kesehatan dimana IMD merupakan acuan awal untuk pemberian air susu ibu (ASI) secara dini, dilanjutkan selama 6 bulan pertama. Gagalnya IMD dan pemberian ASI eksklusif mampu menilbulkan masalah gangguan zat gizi pada bayi, dan akan menjadi ancaman pada masa yang akan datang ${ }^{(13)}$.

$\mathrm{BB} / \mathrm{U}$ adalah berat badan anak yang dicapai pada umur tertentu. Sifat indikator status gizi berdasarkan indeks berat badan menurut umur $(\mathrm{BB} / \mathrm{U})$ dapat memberikan indikasi masalah gizi secara umum karena berat badan berkorelasi positif dengan umur dan tinggi badan. Berat badan menurut umur rendah dapat disebabkan karena pendek (masalah gizi kronis) atau menderita penyakit infeksi (masalah gizi akut) ${ }^{(14)}$ 
Tabel 3. Hubungan Menyusui Dini terhadap Berat Badan Menurut Umur (BB/U)

\begin{tabular}{|c|c|c|c|c|c|c|c|c|c|}
\hline \multirow{3}{*}{ Praktek IMD } & \multicolumn{6}{|c|}{ Berat Badan Menurut Umur } & \multirow{2}{*}{\multicolumn{2}{|c|}{ Total }} & \multirow{3}{*}{$p$} \\
\hline & \multicolumn{2}{|c|}{ Kurang } & \multicolumn{2}{|c|}{ Baik } & \multicolumn{2}{|c|}{ Lebih } & & & \\
\hline & $\mathbf{n}$ & $\%$ & $\mathbf{n}$ & $\%$ & $\mathbf{n}$ & $\%$ & $\mathbf{n}$ & $\%$ & \\
\hline Tidak dilakukan & 3 & 16,7 & 15 & 83,3 & 0 & 0 & 18 & 100 & \\
\hline Dilakukan & 4 & 8,1 & 42 & 85,7 & 3 & 6,1 & 49 & 100 & 0.309 \\
\hline Total & 7 & 10,4 & 57 & 85,1 & 3 & 4,5 & 67 & 100 & \\
\hline
\end{tabular}

Sumber: Data Primer, 2019

Berdasarkan tabel 3, dari 18 yang tidak melakukan praktek IMD di dapatkan 3 orang $(16,7 \%)$ yang berstatus berat badan kurang, 15 orang $(83,3 \%)$ yang berstatus berat badan baik dan tidak di dapatkan yang berstatus berat badan lebih. Sedangkan, dari 49 responden yang melakukan paraktek IMD didapatkan 4 orang $(8,1 \%)$ yang berstatus berat badan kurang, 42 orang $(85,7 \%)$ yang berstatus berat badan baik dan 3 orang yang berstatus berat badan lebih.

Tabel diatas meperlihatkan hasil bahwa praktek Inisiasi Meyusu Dini (IMD) lebih berpotensi anak berstatus gizi baik bilah di bandingkan dengan ibu yang tidak melakukan praktek Inisiasi Meyusu Dini kepadan anak. Penelitan ini sejalan dengan penelitian yang dilakukan oleh Grace Deonita, (2018) yang dilaksanakan di wilayah kerja Puskesmas Pegagan Julu II yang mendapatkan hasil penelitian menunjukkan terdapat $59,1 \%$ ibu yang melaksanakan IMD dan 40,9\% ibu tidak melaksanakan IMD dikarenakan ibu melahirkan secara operasi sesar. Ibu yang memberikan ASI eksklusif kepada bayinya sebesar $43,9 \%$ dan ibu yang tidak memberikan ASI eksklusif sebesar $56,1 \%$ dengan alasan terbanyak adalah pekerjaan ${ }^{(15)}$.

Hasil analisis uji kolmogrov-smirnov diketahui bahwa tidak ada hubungan antara Inisiasi Menyusu Dini terhadap status gizi balita berdasarkan berat badan menurut umur di wilayah Puskesmas Malaka Kelurahan Lapajung Kecamatan Lalabata Kabupaten Soppeng dengan nilai $p(0,309)>0,05$ ini menunjukkan bahwa Ho diterima. Berdasarkan hasil observasi di lapangan diduga penyebab kejadian status gizi kurang disebabkan perilaku hidup yang tidak higenis. Sehingga, pada penelitian ini tidak ditemukannya hubungan IMD dengan status gizi baduta berdasarkan berat badan menurut umur.

Hasil penelitian ini sejalan dengan Ridzal, Hadju, Rochimiwati (2013) yang menyatakan bahwa tidak adanya hubungan antara status IMD dengan status gizi hal ini disebabkan adanya faktor lain yang mempengaruhi status gizi anak pada usia baduta seperti lingkungan sekitar rumah yang kurang bersih, prilaku hidup yang tidak higienis sehingga dapat menyebabkan anak sakit pada waktu tertentu ${ }^{(5)}$.

Namun hasil penelitian ini tidak sejalan dengan penelitian yang di lakukan oleh Eka Diah Kartiningrum (2015) yang menyatakan bahwa ada hubungan antara status IMD dengan status gizi. Hal ini menunjukkan bahwa bayi yang tidak mendapatkan IMD dalam satu jam pertama kehidupannya lebih banyak menderita gizi kurang pada saat berusia enam bulan. Artinya, IMD merupakan faktor risiko status gizi kurang pada bayi usia enam bulan ${ }^{(16)}$.

\section{Inisiasi Menyusu Dini terhadap status gizi berdasarkan Tinggi Badan Menurut Umur (TB/U)}

TB/U adalah tinggi badan anak yang dicapai pada umur tertentu. Sifat indikator status gizi berdasarkan indeks tinggi badan menurut umur $(\mathrm{TB} / \mathrm{U})$ dapat memberikan indikasi masalah gizi yang sifatnnya kronis sebagai akibat dari keadaan yang berlangsung lama. Penyebab satatus gizi ini biasanya disebabkan dengan masalah kemiskinan, perilaku hidup tidak sehat, dan asupan makanan kurang dalam waktu yang lama sehingga mengakibatkan anak menjadi pendek ${ }^{(14)}$. 
Tabel 4 Hubungan Menyusu Dini (IMD) terhadap Tinggi Badan Menurut Umur (TB/U)

\begin{tabular}{|c|c|c|c|c|c|c|c|c|c|c|c|}
\hline \multirow{3}{*}{ Praktek IMD } & \multicolumn{8}{|c|}{ Tinggi Badan Menurut Umur } & \multirow{2}{*}{\multicolumn{2}{|c|}{ Total }} & \multirow{3}{*}{$p$} \\
\hline & \multicolumn{2}{|c|}{ Sangat Pendek } & \multicolumn{2}{|c|}{ Pendek } & \multicolumn{2}{|c|}{ Normal } & \multicolumn{2}{|c|}{ Tinggi } & & & \\
\hline & n & $\%$ & $\mathbf{n}$ & $\%$ & $\mathbf{n}$ & $\%$ & $\mathbf{n}$ & $\%$ & $\mathbf{n}$ & $\%$ & \\
\hline Tidak dilakukan & 3 & 16,7 & 2 & 11,1 & 12 & 66,7 & 1 & 5,6 & 18 & 100 & \\
\hline Dilakukan & 2 & 4,1 & 11 & 22,4 & 32 & 65,3 & 4 & 8,2 & 49 & 100 & 0.457 \\
\hline Total & 5 & 7,5 & 13 & 19,4 & 44 & 65,7 & 5 & 7,5 & 67 & 100 & \\
\hline
\end{tabular}

Sumber: Data Primer, 2019

Berdasarkan tabel 4 di atas menunjukkan bahwa dari 18 responden yang tidak melakukan praktek IMD di dapatkan 3 orang $(16,7 \%)$ yang berstatus tinggi badan sangat pendek, 2 orang $(11,1 \%)$ yang berstatus tinggi badan pendek, 12 orang $(66,7 \%)$ yang berstatus tinggi badan normal dan 1 orang $(5,6 \%)$ yang berstatus tinggi badan tinggi. Sedangkan, dari 49 responden yang melakukan praktek IMD di dapatkan 2 orang $(4,1 \%)$ yang berstatus tinggi badan sangat pendek, 11 orang $(22,4 \%)$ yang berstatus tinggi badan pendek, 32 orang $(65,3 \%)$ yang berstatus tinggi badan normal, dan 4 orang $(8,2 \%)$ yang berstatus tinggi badan tinggi.

Berdasarkan data di atas menunjukkan bahwa tidak dilakukanya praktek Inisiasi Meyusu Dini (IMD) pada ibu ke anak akan memilki peluang mengalami kejadian stunting. Hasil penelitian ini sejalan dengan penelitian yang dilakukan oleh M Rizal Permadi, Diffah Hanim, Kusnandar, dan Dono Indarto, (2016) yang dilaksanakan di Boyolali dengan menggunakan pendekatan cross-sectional dengan partisipan terdiri dari 33 anak stunting dan 77 anak tidak stunting berusia 6-24 bulan. Partisipan anak stunting yang mendapatkan IMD sebanyak 14 orang dan tidak mendapatkan IMD sebanyak 19 orang. Anak stunting yang mendapatkan ASI eksklusif sebanyak 4 orang dan yang tidak sebanyak 29 orang. Penyebab masalah stunting antara lain akibat dari penundaan inisiasi menyusu dini (IMD), dan pemberian air susu ibu (ASI) tidak eksklusif ${ }^{(17)}$.

Hasil analisis uji kolmogrov-smirnov dalam penelitian ini menunjukkan bahwa tidak ada hubungan antara inisiasi menyusu dini terhadap status gizi balita berdasarkan tinggi badan menurut umur di wilayah Puskesmas Malaka Kelurahan Lapajung Kecamatan Lalabata Kabupaten Soppeng dengan nilai $\mathrm{P}$
$(0,457)>0,05$ ini menunjukkan bahwa Ho diterima. Tidak ditemukanya hubungan praktek inisiasi meyusui dini (IMD) dengan tinggi badan menurut umur dikarenakan anak-anak yang mengalami stunting pada tabel 2 sebesar 18 orang $(26,9 \%)$ memiliki riwayat berat badan lahir rendah (BBLR) yang ada di wilayah kerja puskesmas Malaka.

Penelitian ini sejalan dengan penelitian yang di lakukan oleh Frienty Sherlla Mareta Lubis, Risya Cilmiaty, Adi Magna (2018) yang dilaksanakan di 2 kecamatan di Kota Surakarta yang menyatakan bahwa pemberian IMD tidak berhubungan signifikan dengan kejadian stunting $\left(\mathrm{X}^{2}=0,286, \mathrm{p}=0,593\right)$. Akan tetapi yang memberikan hubungan terhadap kejadian stunting di 2 kecamatan di Kota Surakarta yaitu berat badan lahir rendah (BBLR) yang dialami oleh anak-anak yang ada di Surakarta ${ }^{(18)}$.

\section{Inisiasi Menyusu Dini terhadap status gizi berdasarkan Berat Badan Menurut Tinggi Badan (BB/TB)}

$\mathrm{BB} / \mathrm{TB}$ adalah berat badan anak dibandingkan dengan tinggi badan yang dicapai. Sifat indikator status gizi berdasarkan indeks berat badan menurut tinggi badan (BB/TB) dapat memberikan indikasi masalah gizi yang sifatnnya akut sebagai akibat dari peristiwa yang terjadi dalam waktu yang tidak lama (singkat). Misalnya terjadi wabah penyakit dan kekurangan makan (kelaparan) yang menyebabkan anak menjadi kurus. Indikator BB/TB dan IMT/U dapat digunakan untuk identifikasi kurus dan gemuk. Masalah kurus dan gemuk pada umur dini dapat berakibat pada risiko berbagai penyakit degenerative pada saat dewasa (Teori Barker) ${ }^{(14)}$. 
Tabel 5 Hubungan Inisiasi Menyusu Dini terhadap Berat Badan Menurut Tinggi Badan (BB/TB)

\begin{tabular}{|c|c|c|c|c|c|c|c|c|c|c|c|}
\hline \multirow{3}{*}{ Praktek IMD } & \multicolumn{8}{|c|}{ Berat Badan Menurut Tinggi Badan } & \multirow{2}{*}{\multicolumn{2}{|c|}{ Total }} & \multirow{3}{*}{$p$} \\
\hline & \multicolumn{2}{|c|}{ Sangat Kurus } & \multicolumn{2}{|c|}{ Kurus } & \multicolumn{2}{|c|}{ Normal } & \multicolumn{2}{|c|}{ Gemuk } & & & \\
\hline & $\mathbf{n}$ & $\%$ & $\mathbf{n}$ & $\%$ & $\mathbf{n}$ & $\%$ & $\mathbf{n}$ & $\%$ & $\mathbf{n}$ & $\%$ & \\
\hline Tidak dilakukan & 1 & 5,6 & 1 & 5,6 & 16 & 88,9 & 0 & 0 & 18 & 100 & \\
\hline Dilakukan & 0 & 0 & 7 & 14,3 & 40 & 81,6 & 2 & 4,1 & 49 & 100 & 0.202 \\
\hline Total & 1 & 1,5 & 8 & 11,9 & 56 & 83,6 & 2 & 3,0 & 67 & 100 & \\
\hline
\end{tabular}

Sumber: Data Primer, 2019

Berdasarkan tabel 5 di atas menunjukkan bahwa dari 18 responden yang tidak melakukan praktek IMD didapatkan 1 orang $(5,6 \%)$ yang mengalami status sangat kurus, 1 orang $(5,6 \%)$ yang berstatus kurus, 16 orang $(88,9 \%)$ yang berstatus normal, dan tidak di temukan yang berstatus gemuk. Sedangkan, dari 49 responden yang melakukan praktek IMD, tidak didapatkan anak yang berstatus sangat kurus, 7 orang $(14,3 \%)$ yang berstatus kurus, 40 orang $(81,6 \%)$ yang berstatus normal, dan 2 orang $(4,1 \%)$ yang berstatus gemuk.

Berdasarkan data di atas menunjukkan bahwa responden yang melakukan praktek Inisiasi Meyusu Dini (IMD) kepada anak, lebih beresiko anak mengalami kejadian malnutrisi akut bila dibandingkan dengan ibu yang tidak melakukan praktek Inisiasi Meyusu Dini. Menurut Titih Huriah, Laksono Trisnantoro, Fitri Haryanti dan Madarina Julia (2014) menyatakan masalah kekurangan gizi pada anak balita ini merupakan dampak dari rendahnya pemberian ASI eksklusif sampai enam bulan dan pemberian makanan pendamping ASI yang tidak tepat karena diberikan terlalu dini atau terlambat, jumlahnya tidak cukup untuk memenuhi kebutuhan pertumbuhan dan perkembangan bayi pada setiap tahapan usia dan tidak bergizi seimbang untuk memenuhi asupan kalori, protein dan gizi mikro (vitamin dan mineral) ${ }^{(19)}$.

Hasil analisis uji kolmogrov-smirnov pada penelitian ini diketahui bahwa tidak ada hubungan antara inisiasi menyusu dini terhadap status gizi balita berdasarkan berat badan menurut tinggi badan (BB/TB) di wilayah Puskesmas Malaka Kelurahan Lapajung Kecamatan Lalabata Kabupaten Soppeng dengan nilai $\mathrm{P}(0,202)>0,05$ ini menunjukkan bahwa Ho diterima. Hal ini disebabkan anak yang berusia 6-23 bulan yang melakukan praktek IMD dan anak usia 6-23 bulan yang tidak melalukan IMD berpeluang untuk mengalami status sangat kurus, kurus, normal dan gemuk di karenakan bahwa lingkungan tempat tinggal anak yang kurang bersih ditambah dengan perilaku-perilaku keluarga anak yang tidak sehat.

Hal ini semakin diperkuat oleh penelitian yang dilakukan Andi Tenri Abeng, dkk pada tahun 2014 menunjukkan bahwa anak dari keluarga yang memiliki sanitasi lingkungan yang buruk memiliki status gizi yang buruk. Ada beberapa faktor lain yang dapat mempengaruhi status gizi pada anak baduta misalnya lingkungan rumah yang kurang bersih, perilaku hidup tidak sehat yang dapat menyebabkan anak menderita sakit pada waktu tertentu, ${ }^{(20)}$

\section{SIMPULAN DAN SARAN Simpulan}

Berdasarkan hasil penelitian diatas dapat disimpulkan bahwa tidak ada hubungan inisiasi menyusu dini (IMD) terhadap status gizi baduta berdasarkan berat badan menurut umur, tinggi badan menurut umur dan berat badan menurut tinggi badan di wilayah kerja Puskesmas Malaka Kelurahan Lapajung Kecamatan Lalabata

\section{Saran}

Berdasarkan kesimpulan di atas maka disarankan kepada petugas kesehatan agar kiranya terus melakukan edukasi kepada masyarakat dalam peningkatan pengetahuan tentang gizi keluarga dan disarnakan pula kepada masyarakat agar berperilaku hidup bersih dan sehat serta disarnakan kepada para peneliti selanjutnya dengan menambah variabel 
yang lain, misalnya dengan meneliti sanitasi dan pola asuh pada baduta di wilayah kerja Puskesmas Malaka Kelurahan Lapajung Kecamatan Lalabata Kabupaten Soppeng.

\section{REFERENSI}

1. Badan Perencanaan Pembangunan Nasional. Kerangka Kebijakan Gerakan Sadar Gizi dalam Rangka Seribu Hari Pertama Kehidupan (1000 HPK). Jakarta: Bappenas. 2012.

2. Pusat Data Informasi Kementrian Kesehatan RI. Situasi Dan Analisis ASI Eksklusif. Jakarta: Kementerian Kesehatan RI. 2014.

3. Novianti, Mujiati. Faktor Pendukung Keberhasilan Praktik Inisiasi Menyusu Dini di RS Swasta dan Rumah Sakit Pemerintah di Jakarta. J Kesehat Reproduksi. 2015;6(1):3144.

4. DinKes Kabupaten Soppeng. Hasil Pemantauan Status Gizi (PSG) 2017. Dinas Kesehatan Kabupaten Soppeng. 2018.

5. M MR, Hadju V, Rochimiwati S. Hubungan Pola Pemberian ASI dengan Status Gizi Anak Usia 6-23 Bulan di Wilayah Pesisir Kecamatan Tallo Kota Makassar. J MKMI. 2013;1:1-12.

6. Almatsier S, Soetardjo S, Soekatri M. Gizi Seimbang Dalam Daur Kehidupan. Jakarta: Gramedia pustaka utama. 2011. 480 p.

7. Sodiaoetama AD. Ilmu Gizi untuk Mahasiswa dan Profesi (jilid II). Jakarta: Dian Rakyat. 2010.

8. Adriani M, Wirjatmadi B. Peranan Gizi Dalam Siklus Kehidupan. Vol. 2, Jakarta: Kencana Prenada Media Group. 2012. 245-278 p.

9. Supariasa IDN, Bakri B, Fajar I. Penilaian Status Gizi Edisi 2. Jakarta: EGC. 2016.

10. UNICEF Indonesia. Laporan Tahunan Indonesia. Jakarta: Unicef Indonesia; 2015.

11. Kementerian Kesehatan Republik Indonesia. Hasil Pemantauan Status Gizi (PSG) Tahun 2016. Jakarta: Direktorat Bina Gizi Masyarakat,
Dirjen Kesehatan Masyarakat. 2017.

12. Kementrian Kesehatan Republik Indonesia. Modul Pelatihan Penilaian Pertumbuhan Anak. Direktorat Jenderal Bina Gizi dan Kesehatan Ibu dan Anak. Jakarta: Kemenkes RI; 2011.

13. Sirajuddin S, Abdullah T, Lumula SN. Determinan Pelaksanaan Inisiasi Menyusu Dini. Kesmas Natl Public Heal J. 2013;8(3):99-103.

14. Direktorat Gizi Masyarakat Kementerian Kesehatan. Hasil Pemantauan Status Gizi (PSG) Tahun 2017. Jakarta; 2018.

15. Deonita G. Gambaran Pelaksanaan Inisiasi Menyusu Dini (IMD), Pemberian ASI Eksklusif, dan Status Gizi Bayi di Wilayah Kerja Puskesmas Pegagan Julu II. Universitas Sumatera Utara; 2018.

16. Kartiningrum ED. Faktor risiko kejadian gizi kurang pada balita di Desa Gayaman Kecamatan Mojoanyar Mojokerto. Hosp Majapahit (Jurnal Ilm Kesehat Politek Kesehat Majapahit Mojokerto). 2015;7(2):67-80.

17. Permadi MR, Hanim D, Kusnandar K, Indarto D. Risiko Inisiasi Menyusu Dini dan Praktek ASI Eksklusif terhadap Kejadian Stunting pada Anak 6-24 Bulan (Early Breastfeeding Initiation And Exclusive Breastfeeding AS Risk Factors of Stunting Children 6-24 Months-old). Penelit Gizi dan Makanan (The J Nutr Food Res. 2016;39(1):9-14.

18. Lubis FSM, Cilmiaty R, Magna A. Hubungan Beberapa Faktor Dengan Stunting Pada Balita Berat Badan Lahir Rendah. J Kesehat Kusuma Husada. 2018;13-8.

19. Huriah T, Trisnantoro L, Haryanti F, Julia M. Malnutrisi Akut Berat dan Determinannya pada Balita di Wilayah Rural dan Urban. Kesmas Natl Public Heal J. 2014;9(1):50-7.

20. Abeng AT, Ismail D, Huriyati E. Sanitasi, Infeksi, dan Status Gizi Anak Balita di Kecamatan Tenggarong Kabupaten Kutai Kartanegara. J Gizi Klin Indones. 2014;10(3):159-68. 